J. Lake Sci. (湖泊科学), 2014, 26(2):313-321

http: //www. jlakes. org. E-mail : jlakes@niglas.ac.cn

(C) 2014 by Journal of Lake Sciences

\title{
流域社会经济发展对山东省东平湖水环境影响评估及优化调控
}

\author{
后希康 ${ }^{1,4}$, 高 伟 ${ }^{2}$,徐 鹏 $^{3}$, 罗永龙 ${ }^{4}$, 韦亚南 ${ }^{5}$, 营 娜 ${ }^{1}$, 周 丰 $^{6 * *}$ \\ ( 1 : 安徽师范大学国土资源与旅游学院, 芜湖 241000) \\ (2: 北京大学环境科学与工程学院, 水沙科学教育部重点实验室, 北京 100871) \\ (3: 安徽师范大学环境科学与工程学院, 芜湖 241000) \\ (4: 安徽师范大学网络与信息安全工程技术研究中心, 芜湖 241000) \\ (5: 山东省环境保护科学研究设计院, 济南 250013) \\ (6: 北京大学城市与环境学院, 地表过程分析与模拟教育部重点实验室, 北京 100871)
}

摘 要: 针对我国湖泊生态环境保护及“一湖一策”工作的需要, 开展了流域社会经济对东平湖水环境效应评估及联合调 控方案研究. 在基于 “压力一状态一响应”评估方法、系统动力学模拟和情景分析的基础上,全面评估了东平湖当前水平、未 来变化速率和主要瓶颈, 确定了流域社会经济系统调控战略的必要性及潜力、方向和底线. 结果表明:1) 东平湖评估指数 从 2000 年的 52.4 提升到 2010 年的 61.6 ,其评估等级从 III 级提升到 II 级,若仅维持现状水平和高速发展速度,未来 20 年 评估指数将很可能呈现缓慢下降趋势, 长期处于 III 级,甚至达到IV级;2）为了确保维持现状等级及稳中小幅度上升的趋 势,到 2030 年,东平湖流域社会经济发展速度控制在过去 11 年平均增长速度的 $75 \%$,环境响应措施提升到评估标准的 I 级水平;3）建议东平湖的流域生态系统管理工作应先削减已有的和潜在的污染源排放量,随后以自然恢复为主,使湖泊 水质进一步改善.

关键词: 生态安全评估; 系统动力学; 流域管理; 情景分析; 东平湖

\section{Impacts of watershed socio-economic development on Lake Dongping ecosystems of Shandong Province: Assessment and joint-mitigation}

HOU Xikang ${ }^{1,4}$, GAO Wei ${ }^{2}$, XU Peng ${ }^{3}$, LUO Yonglong ${ }^{4}$, WEI Yanan ${ }^{5}$, YING Na ${ }^{1} \&$ ZHOU Feng ${ }^{6}$

(1: College of Territorial Resources and Tourism, Anhui Normal University, Wuhu 241000, P. R. China)

(2: Laboratory of Water and Sediment Sciences, College of Environmental Sciences and Engineering, Peking University, Beijing 100871, P. R. China)

(3: College of Environmental Sciences and Engineering, Anhui Normal University, Wuhu 241000, P. R. China)

(4: Engineering Technology Research Center of Network and Information Security, Anhui Normal University, Wuhu 241000, P. R. China)

(5: Shandong Academy of Environmental Science, Jinan 250013, P. R. China)

(6: Laboratory for Earth Surface Processes, College of Urban and Environmental Sciences, Peking University, Beijing 100871, P. R. China)

Abstract: An assessment approach is proposed to understand the aquatic effects of watershed socio-economic development in order to support Lake Dongping watershed management and its potential solution is identified for joint-mitigation of socio-economic impacts. Different with traditional studies, this integrated framework, including PSR-based assessment, system dynamics and scenario analysis, identifies the current status, future trend and its limited indicators as well as the potential, direction and threshold of joint-mitigation. The results indicate that (i) the assessment index for Lake Dongping was increased from 52.4 ( level III ) at 2000

* 山东省环境保护科学研究设计院项目 (2012)和国家水体污染控制与治理科技重大专项项目(2013ZX07102006)联 合资助. 2013-01-25 收稿;2013-04-16 收修改稿. 后希康(1989 ), 男, 硕士研究生; E-mail: houxikang@ 163. com.

** 通信作者;E-mail:zhouf@ pku. edu.cn. 
to 61.6 (level II ) at 2010, however, the future trend would be decreased slowly in next 20 years and stay at level III or IV for a long time if keeping current high-speed developing rate and control levels, (ii) it was essential to reduce the developing rate at 2030 as about $75 \%$ of average value in past 11 years and to improve the environmental protection as level I required by assessment criteria; and (iii) the roadmap for Lake Dongping watershed should pay more attention to the pollution reductions of current and potential sources following by natural restoration.

Keywords: Ecological security assessment; system dynamics; watershed management; scenario analysis; Lake Dongping

东平湖位于黄河流域下游山东省境内, 流域面积为 $9100 \mathrm{~km}^{2}$, 湖面面积为 $627 \mathrm{~km}^{2}$ (常年有水面积 $\left.124 \mathrm{~km}^{2}\right)^{[1]}$, 包括老湖和新湖两部分 ${ }^{[2]}$, 是山东省第二大淡水湖泊, 也是黄河流域下游仅存的天然湖泊,担 负着黄河滞洪区和重要水源区的作用 ${ }^{[3]}$. 南水北调东线工程投人使用后, 东平湖又成为 “南水北调” 与山东 省“西水东送”输水干线的总枢纽 ${ }^{[4]}$. 因此, 东平湖的水环境保护对缓解北方部分地区水资源短缺问题具有 重要的战略意义 ${ }^{[5]}$.

在人口与经济发展的双重压力下, 东平湖流域的水质现状不容乐观, 富营养化问题逐渐显现 ${ }^{[6-7]} .2010$ 年湖体水质为地表水环境质量 IV 类标准, 主要超标指标为总氮. 相比 $1990 \mathrm{~s}^{[8]}$, 下降了一个水质类别. 根据山 东省污染源普查和统计资料, 2010 年东平湖流域的 COD 和氨氮 $\left(\mathrm{NH}_{3}-\mathrm{N}\right)$ 排放负荷分别达到 13500 和 $608 \mathrm{t}$, 主要源于工业、生活点源和农业面源排放. 东平湖流域密集的人口与相对初级的生产方式 ${ }^{[4,9]}$ 对其水环境形 成了巨大的压力. 从土地利用方式看, 耕地占土地总面积的 60\%, 农业面源污染风险显著; 从产业结构来看, 2010 年流域内三大产业的比值为 8:56:36, 仍以工业为主要的产业类型, 区域内工业结构性污染较为突出, 重污染行业依然是工业点源的主要污染来源. 在 “十八大” 的 GDP 和居民收人翻番目标驱动下, 经济社会发 展相对落后的东平湖流域可能进入城镇化、工业和农业现代化加速阶段, 未来的经济规模扩张对东平湖的 水环境将形成更大的潜在压力.

鉴于此, 有必要从经济社会一水环境耦合角度, 评估东平湖的水环境变化趋势并识别其主要瓶颈, 提出 经济社会发展目标与水环境保护目标双重约束下的发展新模式. 本文基于 “压力一状态一响应”评估方法,构 建经济社会与水环境之间的响应模式, 在系统动力学模型基础上, 模拟经济目标与水环境目标之间的制约 与反馈关系, 甄别适宜的发展情景分析, 以期为东平湖经济社会与水环境协调发展提供一种选择与参考.

\section{1 数据与方法}

本研究使用的方法包括评估、模拟与情景分析 3 类, 其中评估是基于 PSR “压力一状态一响应”框架建立 东平湖流域经济社会对水环境影响的评估体系, 识别东平湖存在的主要问题, 该方法主要涉及指标选择、评 价标准、指标综合和不确定性分析等内容; 模拟的目的是表征经济社会与水环境的反馈关系, 为评估不同发 展模式对水环境的影响提供方法支持, 本研究采用 SD 模型建立了 “源头一过程一未端一水体” 的响应关系; 情 景分析是在评价与模拟方法的基础上,测试未来不同发展模式下经济社会与水环境的变化, 识别适用发展 方案.

\section{1 评估方法}

1.1 .1 指标选择 依据 PSR “压力一状态一响应” 指标体系框架 ${ }^{[10-12]}$, 其中压力指标主要从人口规模与结构、 生活水平、资源占用量角度选取; 状态层应考虑水质常用评估指标和生态水量指标; 响应层考虑污染物排放 强度、污染治理水平、生态措施等方面指标. 同时参考湖泊生态安全评估的相关指标 ${ }^{[13-17]}$, 根据数据可得性, 选择了 18 项指标 (表 1 ).

1.1 .2 评估标准与等级划分 评估标准是确定指标优劣的判别标准. 对于大多数指标, 以评估时间范围内全 国各省数据序列的 $10 \% 、 90 \%$ 分位数作为最劣或最优值 (取决于指标是正向还是负向), 其对应标准值分别 为 0 分和 100 分; 部分指标参考历史水平和环境指标, 选择评估时间范围内的最优值或最劣值. 基于此, 可以 对各方案层的各指标进行标准化处理 (本研究采用极差法 ${ }^{[22]}$ ). 等级划分考虑与当前我国湖泊生态评估的 需要相匹配 ${ }^{[13]}$, 本文同样划分为 5 个等级, $V \sim$ I 级分别对应着“严重” ( $0 \sim 20$ 分)、“较重” ( $20 \sim 40$ 分)、 “一般” (40 60 分)、“较轻” (60 80 分) 和“轻微” (80 100 分). 
表 1 东平湖社会经济综合影响指数评估指标和数据来源

Tab. 1 Index on the aquatic effects and data source of Lake Dongping watershed socio-economic development

\begin{tabular}{|c|c|c|}
\hline 方案层 & 具体指标 & 数据来源 \\
\hline 压力层 & $\begin{array}{l}\text { 人口密度 }{ }^{1)} \text { 、人均 } \mathrm{GDP}^{2)} \text { 、城镇化率 }{ }^{3)} \text { 、人均耕地面积 }{ }^{4)} \text { 、人均水资 } \\
\text { 源量 }^{5)}\end{array}$ & \multirow{3}{*}{ 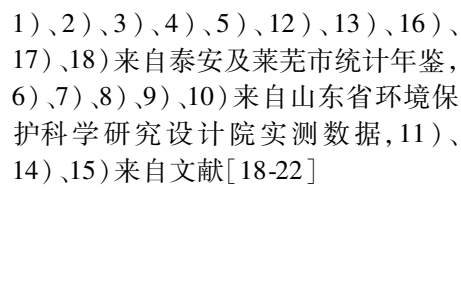 } \\
\hline 状态层 & $\begin{array}{l}\text { 总氮 }{ }^{6)} \text { 、总磷 }{ }^{7)} \text { 、高锰酸盐指数 }{ }^{8)} 、 \mathrm{NH}_{3}-\mathrm{N}^{9)} \text { 、叶绿素 } \mathrm{a}^{10)} \text { 、生态需水保 } \\
\text { 证率 }^{11)}\end{array}$ & \\
\hline 响应层 & $\begin{array}{l}\text { 单位 GDP 工业氨氮排放量 }{ }^{12)} \text { 、单位 GDP 工业 COD 排放量 }{ }^{13)} \text { 、湿地 } \\
\text { 面积占流域面积比重 }{ }^{4)} \text { 、规模化畜禽养殖场粪便集中处理率 }{ }^{15)} \text { 、城 } \\
\text { 镇生活污水集中处理率 }{ }^{16)} \text { 、中水回用率 }{ }^{17)} \text { 、化肥施用强度 }{ }^{18)}\end{array}$ & \\
\hline
\end{tabular}

1.1 .3 指标综合方法 加权算术平均法 ${ }^{[17]}$ 是湖库、河流、海洋生态安全或健康评估常用的方法之一 ${ }^{[23]}$, 采用 该方法确定流域社会经济的水环境效应评估指数 (Index), 其计算公式为:

$$
\text { Index }=\sum_{i=1}^{I} \sum_{j=1}^{J}\left(\omega_{i} \cdot \omega_{j} \cdot x_{i j}\right) \times 100
$$

式中, $x_{i j}$ 为第 $i$ 个方案层的第 $j$ 个指标; $\omega_{i}$ 和 $\omega_{j}$ 分别为各方案层和各指标的权重. 权重可采用等权方式 ${ }^{[24]}$, 也可以采用多准则群体决策等模型 ${ }^{[25-27]}$. 本研究中, 权重是通过问卷调查后平均化处理来确定的.

1.1 .4 不确定性估计 不确定性在环境问题中普遍存在 ${ }^{[28]}$, 公式 $(1)$ 中的权重 $\left(\omega_{i}\right.$ 和 $\left.\omega_{j}\right)$ 和指标值 $\left(x_{i j}\right)$ 也 是存在不确定性的, 将对最终的评估指数计算结果产生影响. 因此, 需要进行不确定性估计, 即在 $N(u, \sigma)$ 和权重之和 $\sum \omega_{i}$ 或 $\omega_{j}=1$ 约束下对权重 $\left(\omega_{i}\right.$ 和 $\left.\omega_{j}\right)$ 和指标值 $\left(x_{i j}\right)$ 进行 Monte Carlo 随机采样, 选择 Index 的 $R_{80}$ (等于 $10 \%$ 和 $90 \%$ 分位数的差值) 为其不确定性水平 ${ }^{[29]}$.

\subsection{SD 系统模拟}

1.2.1 东平湖 “经济社会一水环境” SD 模型 本研究以 Vensim ${ }^{\circledR}$ DSS 作为建立模型和模拟仿真的平台, 以此 回答流域社会经济发展对东平湖水生态系统的影响途径、强度及演变规律, 识别影响优化调控的敏感性评 估指标, 定量评估人口、产业、土地利用方式和水污染控制的规模、速度、结构和布局调整对东平湖水环境的 响应. 依据社会经济与水生态环境的作用方式及相应污染源类型, 将东平湖研究系统划分为 6 个子系统 (图 1 ): 城镇生活、农村生活、农业种植业、畜牧业、工业和水环境子系统. 从“压力一状态一响应角度建立了每个子 系统的发展规模、用水量、排污量和水环境响应模块.

1.2.2 模型设置 模型边界为东平湖流域, 涉及 7 个县 (区), 共 $9100 \mathrm{~km}^{2}$. 系统模拟的时间边界为 $2010-$ 2030 年, 以 2010 年为基准年,模拟时间间隔为 1 年.

1.2 .3 灵敏度分析 基于建立的东平湖社会一经济一水环境系统动力学模拟模型, 可以测试相关经济社会和 评估体系中各层的变化对东平湖的影响, 获得它们的敏感度, 从而识别各层在未来调控战略中可能的影响 与潜力. 由于调控不同指标对东平湖经济社会评估中的方案层和目标层影响存在较大差异, 因此根据各个 指标的可能变动范围, 可计算出它们相应的调控潜力, 即某项指标调控对东平湖流域的综合影响最大改善 能力或可能的压力. 指标的调控潜力计算公式如下:

$$
P_{i}=S_{i} \cdot \Delta Q_{i}
$$

式中, $P_{i}$ 为指标 $i$ 的调控效果潜力; $S_{i}$ 为指标灵敏度, 即单位指标数值变化对调控目标的影响; $\Delta Q_{i}$ 为指标的 可能变化幅度.

\section{3 情景分析法}

考虑未来可能的经济社会和环境保护发展趋势与要求, 设计了经济社会与水环境发展的低、中、高情景 组合方案. 情景方案设计从平面上看是一个平面二维结构, 其 $\mathrm{X}$ 轴是环境措施维, 该维度根据措施力度的大 小分为低目标 (B1)、中目标 (B2) 和高目标 (B3)3 种水平, 表征地方政府对环境保护的重视程度; Y 轴是经 济社会维,反映不同经济社会发展目标,也分为低目标 (A1)、中目标 (A2) 和高目标 (A3) 3 种水平,表征地方 


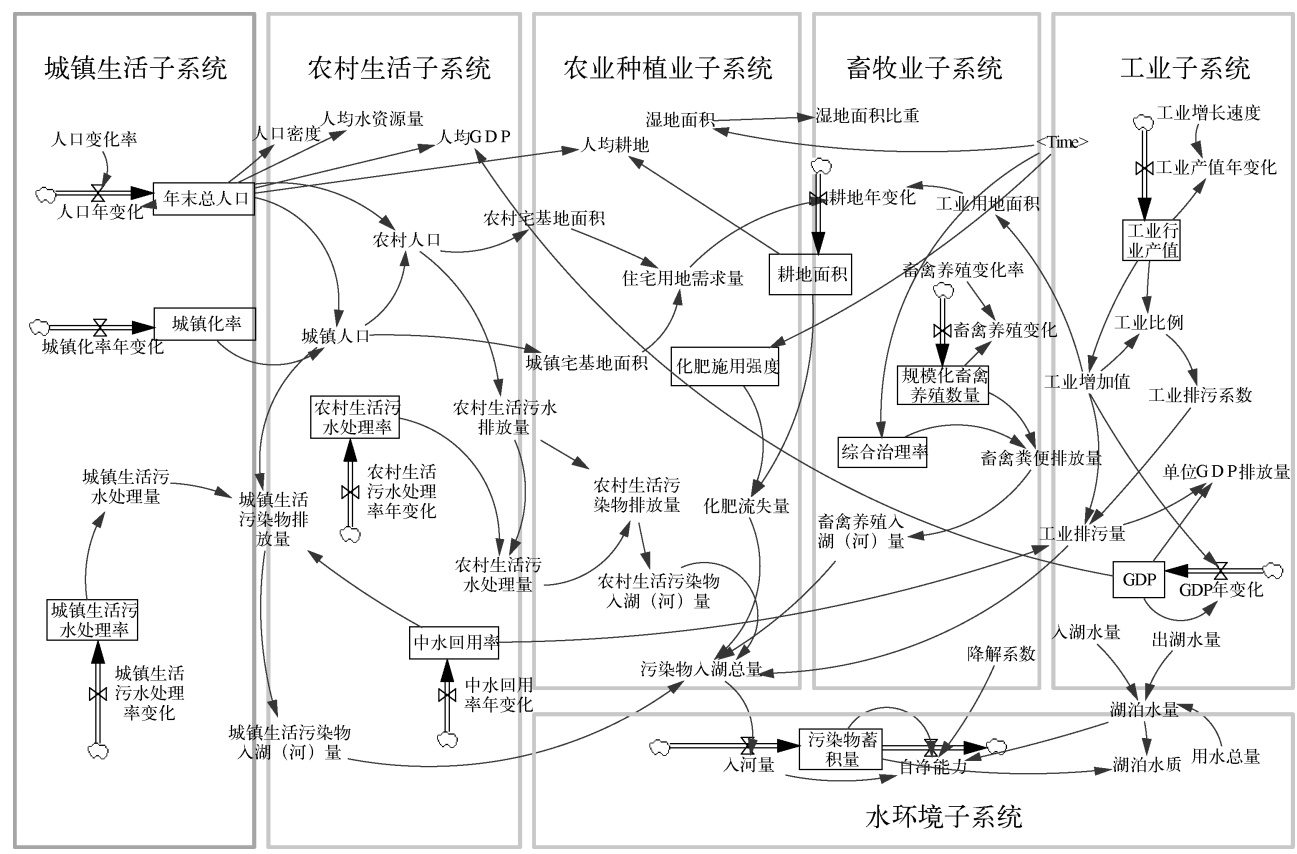

图 1 东平湖社会经济一水环境耦合 SD 系统

Fig. 1 Systematic dynamic model of Lake Dongping society-economy-water coupled system

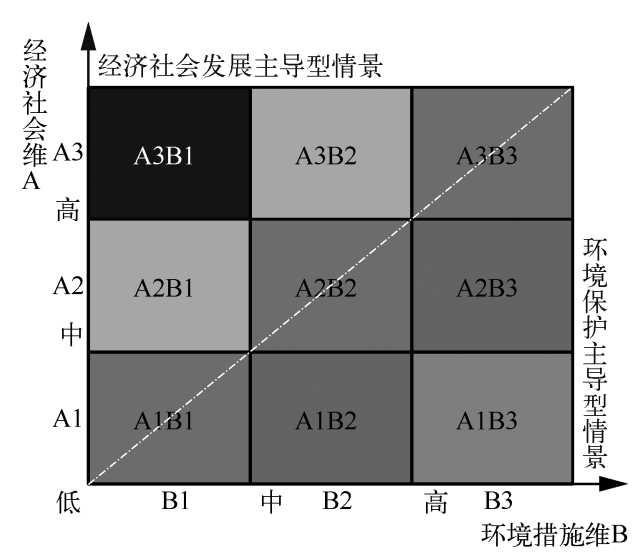

图 2 东平湖情景方案设计框架

Fig. 2 Framework of scenario devise for Lake Dongping

政府对经济社会发展的期望. 通过不同目标的交叉组 合,可生成 9 种发展情景. 以上的 9 种情景涵盖了经济 社会与环境保护在不同发展水平的多种可能组合, 可为 东平湖发展战略提供一定的参考与指导. 设计了 9 种发 展情景(图 2).

\section{2 结果与讨论}

\section{1 流域社会经济发展对东平湖水环境影响历史评估}

按照 1.1 部分的方法,得到东平湖流域社会经济的 水环境效应评估指数. 从历史水平来看, 评估指数在 $2000-2010$ 年整体呈现上升趋势, 只是在 2003 年 (47. 1) 存在下降,主要原因为: 南水北调东线工程 2002 年 12 月 27 日正式开工建设, 而东平湖是南水北调东线 工程的最后调蓄湖泊, 湖泊的水量、水速等一些水文条 件受到影响, 导致水质下降. 整体上看, 从 2000 年的 52.4 提升到 2010 年的 61.6 , 其评估等级从 III 级 “一般” 提升 1 个等级, 达到 II 级 “较轻”, 此上升趋势和增长速率显著优于太湖、巢湖和滇池 ${ }^{[13,30-31]}$. Index 的不确定 性估计 $R_{80}$ 相比中位值仅偏差 1\% 5\% (图 3), 表明权重对 Index 影响甚微, 计算结果相对可靠.

从 3 个方案层变化看 (图 4), 压力层和响应层整体上呈现上升趋势, 状态层则相反. 东平湖流域调控 “响应” 在 2002 年 $(44.0)$ 和 2008 年 (60.5) 存在 2 个“跳跃式”提升, 这主要得益于山东省政府在过去 10 年 逐步提出的东平湖流域 “治、用、保” 的治污思路, 以及 2006 年通过的《山东省南水北调工程沿线区域水污染 防治条例》和制定的《山东省南水北调沿线水污染物综合排放标准》, 很大程度地缓解了社会经济发展所带 来的水环境压力 ${ }^{[32]}$. 


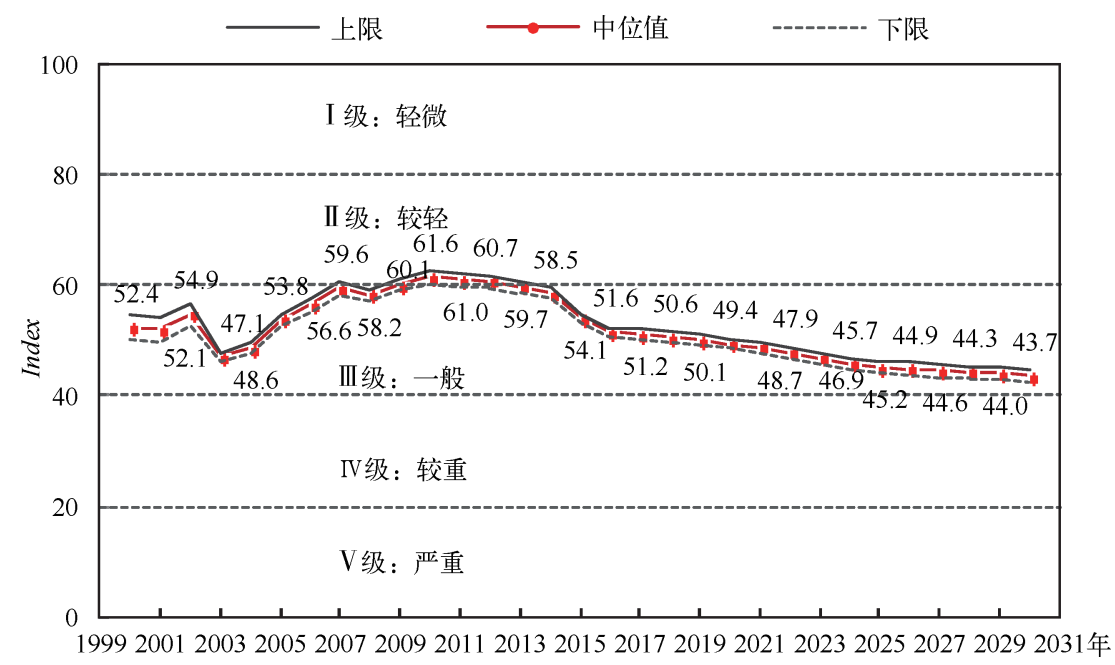

图 3 东平湖流域社会经济的水环境效应评估指数历史和未来演变及不确定性估计

Fig. 3 Past and future trends of Index on the aquatic effects of Lake Dongping watershed socio-economic development with its uncertainty estimations

各个指标对方案层的贡献存在明显差别 (图 4). 对于社会经济发展 “压力” 而言,2000-2010 年其主要 制约因素是人均水资源量 $\left(432.1 \pm 6.5 \mathrm{~m}^{3} /\right.$ 人) 和人口密度 $\left(651.2 \pm 9.8\right.$ 人 $\left./ \mathrm{km}^{2}\right)$, 支撑“压力” 层缓慢上升 的原因是流域人均 GDP 的快速提高. 从未来的预测来看, 2011-2030 年间,社会经济发展“压力”的限制指 标依然是人均水资源量和人口密度, 其正面贡献趋向于最劣值, 当然人均 GDP 及其贡献皆逐年上升, 缓解了 压力层的下降速度 (图 5). 东平湖水环境 “状态” 中的各项指标对状态层的贡献一直保持不变或者下降, $\mathrm{NH}_{3}-\mathrm{N}$ 和高锰酸盐指数下降幅度较大. 而在 “响应” 中, 各项指标对其贡献基本保持不变, 尤其是单位 GDP 工业 COD 排放量和氨氮排放量已经将近达到最优值 100. 从未来演变来看, 参考当地 4 个城市各自的总体 规划, 得出人口密度、人均 GDP 和城镇化率将会进一步提高, 人均耕地面积则会持续下降, 而人均水资源量 将随着南水北调东线工程的实施有所改善. 对于东平湖水环境 “状态”而言, 东平湖水质显著改善, 除 TN 外 均达到了地表水 III 类水质标准. 对于东平湖流域调控 “响应”而言,主要得益于工业废水治理、生活污水处理 和退田还湿工程,然而,农业污染源 (含种植业和畜㥐养殖业) 和中水回用还有较大控制或利用空间.
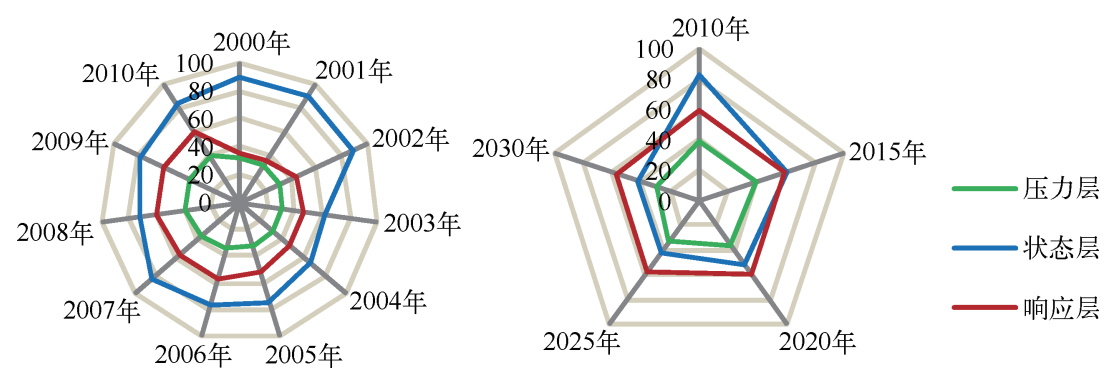

图 $42000-2030$ 年东平湖方案层指数演变趋势及贡献水平

Fig. 4 Past and future trends of Index of criteria level and its contribution to goal level during 2000 - 2030

此外,从 Index 的未来动态演变趋势上看 (按现状发展趋势), 在 2015 、2020 和 2030 年分别下降到 54. 1、 49.4 和 43.7 , 尽管处于 III 级 “一般”, 但呈现缓慢下降趋势, 有可能达到 IV 级 “较重” 的等级水平. 3 个方案层 整体上出现下降趋势, 但是下降的幅度并不是同步的(图 5 ). 

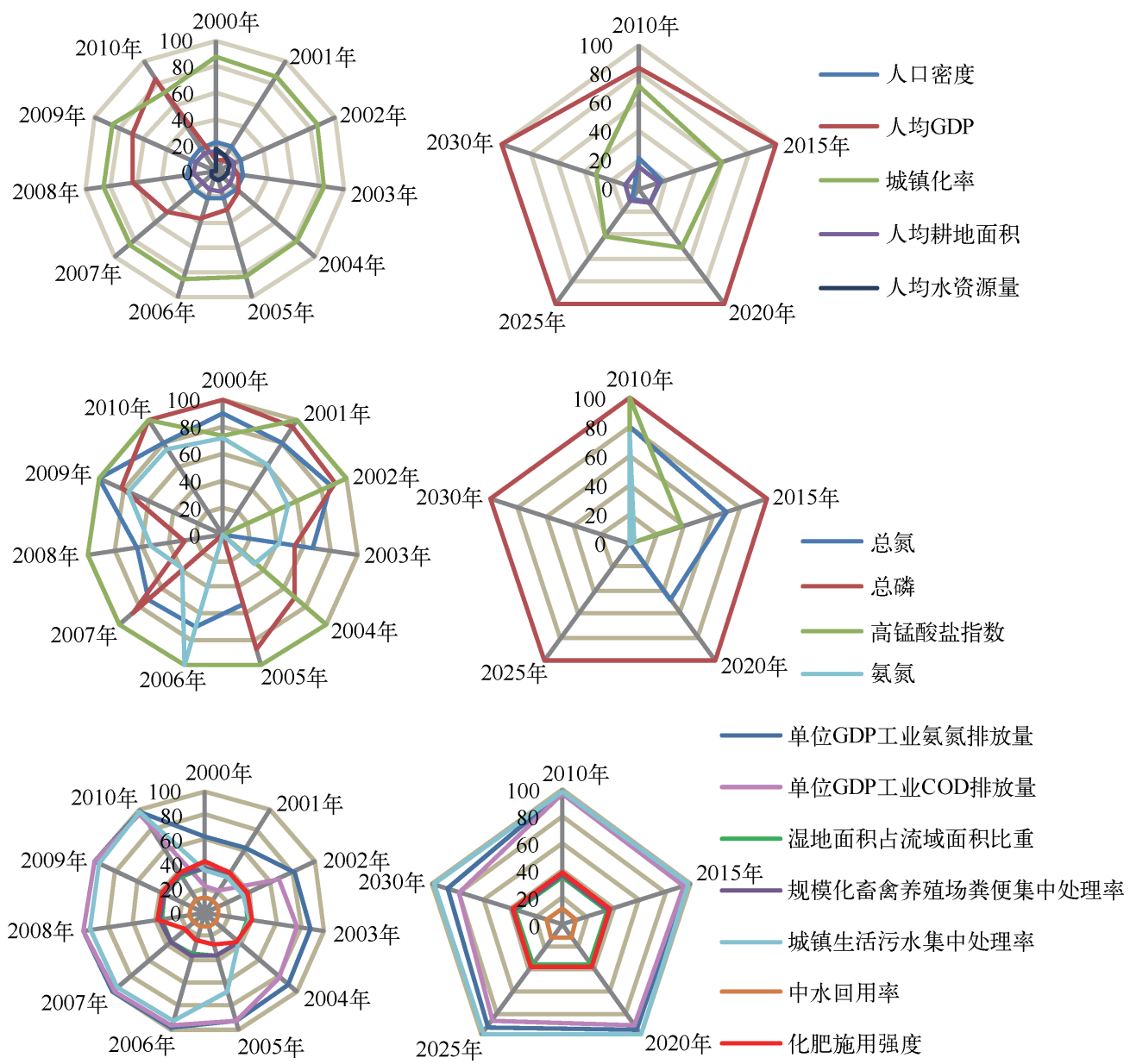

图 5 东平湖流域 “压力一状态一响应” 各指标历史及未来对方案层的贡献水平

Fig. 5 Past and future trends of standardized indicators and its contribution for criteria level in Lake Dongping watershed

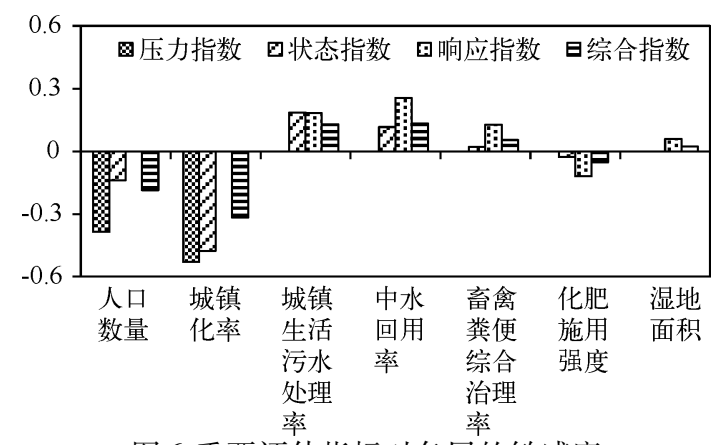

图 6 重要评估指标对各层的敏感度

Fig. 6 Sensitivity of assessment index to key standardized indicators

\section{2 东平湖社会经济系统调控潜力}

为了识别各项调控指标变化对方案层和目标 层的影响,计算了指标变化幅度 $10 \%$ 时 (规模指 标为现状值的 $10 \%$, 结构类指标为实际变动幅 度), 压力、状态、响应和综合指数的变化幅度 (图 6 ). 从各项调控指标看, 城镇生活污水集中处理 率、中水回用率、畜禽粪便综合治理率、农村生活 污水处理率等是重要的敏感指标, 对各层的敏感 度较高, 呈现正效应.

为了计算调控潜力, 必须首先确定压力层和 响应层指标的取值上限 (正向指标) 或下限 (负向 指标). 调控的指标包括人口与工业结构类指标 (8 个)、污水治理水平类指标 (5 个)、生态类指标

(2 个), 共 15 项. 其中, 人口与工业结构类指标的取值主要依据历史变化趋势确定; 污染治理水平类指标主 
要是污水处理率、中水回用率等, 其变化的极限值主要参考国内先进水平和相关环境标准要求; 生态类指标 主要考虑湿地面积和农田化肥施用强度两项指标, 其变化极限主要考虑地方规划和现状发展水平. 经计算, 单项指标对水环境效应评估指数的提升潜力差异很大, 提升能力范围为 - 5.7 5.9. 综合各项指标的整体 潜力,到 2030 年 Index 可提升 7.9, 达到 69.5. 因此,在适当的经济社会与环境政策影响下,东平湖未来的水 环境效应评估指数仍有提升的空间.

\section{3 东平湖流域系统情景分析与调控底线}

在一定的措施组合下, 流域的社会经济综合影响评价指数的等级有望进一步提高, 情景模拟与评估结 果表明（图 7):9 个情景中有 2 个情景的综合影响指数 Index 不断上升 (A1 B2、A1 B3),2 个情景的综合影响 指数在 61 左右波动 $(A 1 B 1 、 A 2 B 3)$,其他 5 个为下降趋势. 从压力指数的变化看,所有的 9 个情景均表现出 逐年下降趋势, 体现经济社会规模的增大对流域形成的压力是不断提高的, 这是流域人口增长与城市化水 平提高等基本发展要求的必然结果. 从状态层指数的变化看, 9 个情景之间变化较为复杂,到 2030 年,有 3 个情景可维持在轻微影响的等级水平附近, 6 个处于 III 级, 其与经济社会规模呈反比,与环境保护措施力度 呈正比. 从响应指数的变化看, 9 个情景的响应指数 (除 $\mathrm{A} 3 \mathrm{~B} 1$ 外) 均呈现稳定的增长趋势, 响应指数的变化 对综合指数有促进作用, 是综合指数提升的主要驱动力.

以东平湖未来社会经济一水环境系统优化发展为原则, 本研究认为东平湖的发展阈值制定应满足东平 湖未来的综合影响指数逐年提高, 且 3 个方案层的指数维持现状等级有所提高的要求, 同时考虑到该流域 的社会经济发展和采取相应的环境保护措施相互之间的协调关系,满足条件的只有 A1B1 和 A2B3 方案情 景. 但十八大报告明确指出, 到 2020 年实现国内生产总值和城乡居民收人翻番的量化指标, 所以, 中目标社 会经济发展和高目标环境治理水平的情景组合 A2B3 构成了东平湖社会经济发展和环境保护的底线. 相应 地,东平湖社会经济优化调控措施的各项指标应优于 A2B3 的各项参数 (表 2).

因此,在对东平湖流域经济社会各项指标调控的同时,应加强对响应层各项指标的调控: (1) 完善城镇 污水处理体系,提高负荷削减能力. 以整个东平湖流域城镇污水收集率和集中处理率为工作重点,一方面提 高城镇生活污水收集率和处理率, 另一方面开展农村生活污水处理工程. (2) 提高中水回用率, 缓解水资源 压力. 节约用水, 强化并严格推行城市再生水利用设施建设的相关法规, 完善各类水资源利用价格体系, 着
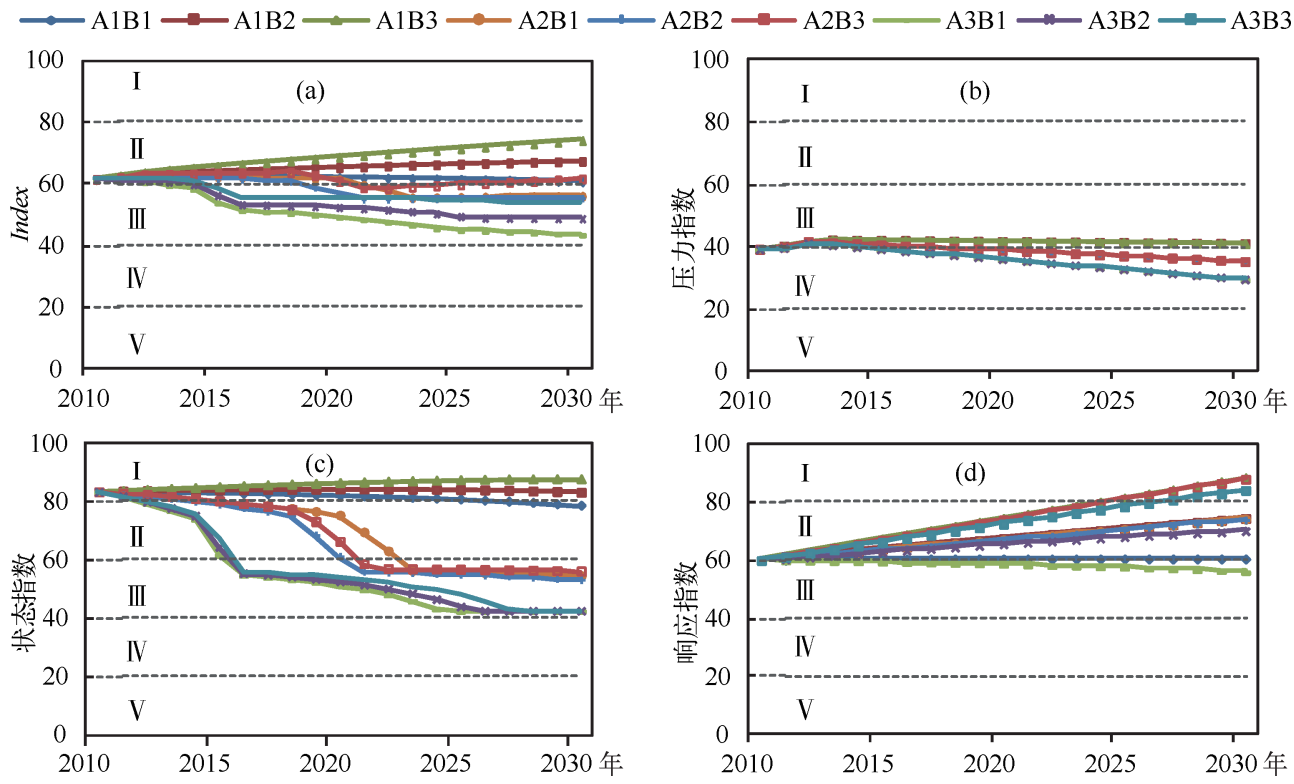

图 $72010-2030$ 年东平湖综合评价指数的情景矩阵

Fig. 7 Index predict of different scenarios in Lake Dongping watershed during 2010 - 2030 
手进行污水处理厂再生水利用和城市再生水利用设施建设, 加快建设尾水再生利用系统, 城镇景观、绿化、 道路冲酒等优先利用再生水, 逐步建立和健全与城市水系统相协调的城市再生水利用的管网系统以及集中 处理厂出水、单位建筑中水、居民小区中水相结合的再生水利用体系. (3) 提高畜禽粪便综合治理率, 减少 畜禽养殖污染负荷. 东平湖流域适当划分禁养区, 控制养殖规模, 政府对 “禁养” 对养殖户造成的经济损失进 行核算和补偿, 扶持建设转移养殖区和养殖户搬迁新建工作.

表 2 东平湖经济社会调控阈值

Tab. 2 Baseline of socio-economic development adjustment for Lake Dongping watershed

\begin{tabular}{clcccccc}
\hline 指标类型 & 指标 & 单位 & 2010 年 & 2015 年 & 2020 年 & 2025 年 & 2030 年 \\
\hline \multirow{2}{*}{ 人口 } & 人口数量 & 万人 & 601.48 & $\leqslant 620.06$ & $\leqslant 639.20$ & $\leqslant 658.93$ & $\leqslant 679.28$ \\
& 城镇化率 & $\%$ & 38.45 & $\leqslant 40.51$ & $\leqslant 42.57$ & $\leqslant 44.63$ & $\leqslant 46.70$ \\
工业结构 & 化学原料和化学制品制造业 & 亿元 & 502.42 & $\leqslant 842.80$ & $\leqslant 1413.00$ & $\leqslant 2371.00$ & $\leqslant 3978.00$ \\
& 有色金属冶炼和压延加工业 & 亿元 & 459.45 & $\leqslant 781.21$ & $\leqslant 1328.00$ & $\leqslant 2258.00$ & $\leqslant 3840.00$ \\
& 黑色金属矿采选业 & 亿元 & 53.25 & $\leqslant 106.17$ & $\leqslant 211.70$ & $\leqslant 422.13$ & $\leqslant 841.70$ \\
& 电力、势力生产和供应业 & 亿元 & 22.29 & $\leqslant 28.85$ & $\leqslant 37.35$ & $\leqslant 48.36$ & $\leqslant 62.61$ \\
& 黑色金属冶炼和压延加工业 & 亿元 & 40.75 & $\leqslant 63.56$ & $\leqslant 99.15$ & $\leqslant 154.67$ & $\leqslant 241.28$ \\
& 其他行业 & 亿元 & 380.83 & $\leqslant 756.06$ & $\leqslant 1500.00$ & $\leqslant 2979.00$ & $\leqslant 5915.00$ \\
水污染控制 & 规模化畜禽养殖规模 & $\%$ & 83.60 & $\geqslant 86.44$ & $\geqslant 89.30$ & $\geqslant 92.15$ & $\geqslant 95.00$ \\
& 城镇生活污水处理率 & 万头 & 408.60 & $\leqslant 421.42$ & $\leqslant 434.65$ & $\leqslant 448.29$ & $\leqslant 462.36$ \\
& 农村生活污水处理率 & $\%$ & 0 & $\geqslant 17.5$ & $\geqslant 35.0$ & $\geqslant 52.5$ & $\geqslant 70.0$ \\
& 中水回用率 & $\%$ & 6 & $\geqslant 17$ & $\geqslant 28$ & $\geqslant 39$ & $\geqslant 50$ \\
& 畜禽粪便综合治理率 & $\%$ & 35 & $\geqslant 50$ & $\geqslant 65$ & $\geqslant 80$ & $\geqslant 95$ \\
& 化肥施用强度 & $\mathrm{kg} / \mathrm{hm}^{2}$ & 582 & $\leqslant 499$ & $\leqslant 416$ & $\leqslant 333$ & $\leqslant 250$ \\
& 湿地面积 & $\mathrm{km}^{2}$ & 634 & $\geqslant 642$ & $\geqslant 650$ & $\geqslant 658$ & $\geqslant 666$ \\
\hline
\end{tabular}

\section{3 结论}

1) 从整体上看, 东平湖流域社会经济的水环境效应评估指数 (Index) 过去 11 年呈现上升趋势, 但在 2003 年 (47. 1) 存在大幅度下降. 从 2000 年的 52.4 提升到 2010 年的 61.6 , 其评估等级从 III 级提升到 II 级, 若仅维持现状水平和高速发展速度, 未来 20 年 Index 将很可能呈现缓慢下降趋势, 长期处于 III 级, 甚至达到 IV 级.

2) 该评估方法对东平湖流域社会经济的水环境效应进行综合性评估, 不仅对历史进行了评估, 还对未 来进行了动态预测, 从而为决策者提供了依据. 建议到 2030 年, 东平湖流域社会经济发展速度控制在过去 11 年平均增长速度的 $75 \%$, 环境响应措施提升到评估标准的 I 级水平, 则可能维持现状等级或稳中小幅度 上升趋势. 建议东平湖流域水环境保护工作将分两个阶段进行: 第一阶段, 先整治环境污染, 清理和整治已 有的和潜在的污染源, 降低污染风险; 第二阶段, 保护整治成果, 建立长期保护机制, 以自然恢复为主, 使湖 泊水质进一步改善.

3) 事实上, 由于作者认知水平有限, 本方法必然存在不足, 由于各地社会经济发展水平、土地利用方式 和产业结构等一些因素的差异, 使不同湖泊面临的环境问题也不尽相同, 故此方法需要在广泛应用中逐步 检验、修正和完善,从而解决“人湖”关系, 实现“一湖一策”.

\section{4 参考文献}

[1 ] 江恩惠,李军华,董其华. 东平湖水库未来战略地位探讨. 中国水利, 2009, (23):7-11.

[ 2] 张 欣, 喻宗仁, 赵培才等. 南水北调东平湖水质变化趋势分析研究. 中国环境监测, 2004, 20 (4):46-48.

[ 3 ] 侯世文,元修增, 李振苓等. 水污染与东平湖水资源可持续利用探讨. 人民黄河, 2006,28(7):32-33.

[ 4 ] 陈兆开. 南水北调东线东平湖库区生态经济可持续发展研究. 生态经济, 2009, (11):62-64.

[ 5 ] 罗辉, 欧阳越, 周建仁. 南水北调东平湖水质分析与治理对策. 水利水电技术, 2003,34(11): 18-20. 
[6] 何德进,邢友华,姜瑞雪等. 东平湖水体中氮磷的分布特征及其富营养化评价. 环境科学与技术, 2010,33(8): $45-48$.

[ 7 ] 陈永金,林 丽,刘加珍等. 东平湖水体环境容量分析. 人民黄河,2012,34(6):61-62.

[8] 陈诗越,董 杰, 张重阳. 东平湖生态环境现状及流域可持续发展对策研究. 安徽农业科学, 2007,35 (5): 1436-1437.

[9] 余文学,殷建军. 东平湖库区可持续发展综合分析. 中国人口.资源与环境,2003,13(4):76-80.

[10］任建丽,金海龙,叶 茂等. 基于 PSR 模型对艾比湖流域生态系统健康评价研究. 干旱区资源与环境,2012,26(2)： 37-41.

[11］李中才,刘林德,孙玉峰等. 基于 PSR 方法的区域生态安全评价. 生态学报,2010,30(23):6495-6503.

[12］颜 利,王金坑,黄 浩. 基于 PSR 框架模型的东溪流域生态系统健康评价. 资源科学,2008,30(1):107-113.

[13] 中国环境科学研究院.湖泊生态安全调查与评估. 北京:科学出版社,2012.

[14] 金相灿,王圣瑞,席海燕. 湖泊生态安全及其评估方法框架. 环境科学研究,2012,25(4):357-362.

[15] 朱 凌,王举位,桂 凌等. 基于生态威胁的湖泊生态安全指标体系研究. 安徽农业科学, 2011,39(11):6649-6650.

[16] 郭树宏,王菲凤,张江山等. 基于 PSR 模型的福建山仔水库生态安全评价. 湖泊科学,2008,20(6):814-818.

[17] 王丽婧,郑丙辉. 水库生态安全评估方法 ( I ) : IROW 框架. 湖泊科学, 2010,22(2):169-175.

[18］贾传义. 东平湖区域水资源综合利用战略研究. 地下水,2008,30(2):98-102.

[19］崔保山,杨志峰. 湿地生态环境需水量等级划分与实例分析. 资源科学,2003,25(1):21-28.

[20] 于少鹏,孙广友,孙雅萍等. 南水北调东线工程沿线湖沼湿地生态环境特征及退化分析. 资源科学, 2005,27(2): 121-127.

[21］吕宝平,贾德旺,田文新等. 山东省湿地类型及湿地环境地质问题分析. 山东国土资源,2008,24(4):44-47.

[22］山东省环境保护局. 山东省淮河流域地表水环境容量核定技术报告. 2005.

[23］王好芳,董咏梅,宋苏林. 基于模糊聚类分析的地表水环境变化趋势评价. 人民黄河,2009,31(8):48-49.

[24] Halpern BS, Longo C, Hardy D et al. An index to assess the health and benefits of the global ocean. Nature, 2012, 488 $(7413): 615$.

[25] 陈守显. 模糊水文学与水资源系统模糊优化原理. 大连: 大连理工大学出版社, 1990 .

[26] Yang JS, Chung ES, Kim SU et al. Prioritization of water management under climate change and urbanization using multicriteria decision making methods. Hydrology and Earth System Sciences, 2012, 16(3) : 801-814.

[27] Bisdorff R. Cognitive support methods for multi-criteria expert decision making. European Journal of Operational Research, 1999, 119 (2) : 379-387.

[28] Ananda J, Herath G. A critical review of multi-criteria decision making methods with special reference to forest management and planning. Ecological Economics, 2009, 68(10) : 2535-2548.

[29] Dantzig GB. Linear programming under uncertainty. Management Science, 1955, 1(3/4) : 197-206.

[30］陶 澍. 应用数理统计方法. 北京: 中国环境科学出版社, 1994.

[31] 刘 庄,郑 刚,张永春等. 社会经济活动对太湖流域的生态影响分析. 生态与农村环境学报,2009,25(1):27-31.

[32] 冯 宁,毛 锋,李晓阳等. 滇池生态安全综合评估研究. 环境科学,2010,31(2):282-286.

[33] 梁春玲,张祖陆,牛玉生. 南四湖水安全评价研究. 安徽农业科学,2009,37(7):3178-3181. 